\title{
Identification and Characterization of Chemical Compounds that Inhibit Leucyl-tRNA Synthetase from Pseudomonas aeruginosa
}

\author{
Regina Zamacona ${ }^{1}$, Pamela N. Chavero' ${ }^{1}$, Eduardo Medellin ${ }^{1}$, Yanmei Hu${ }^{1,2}$, Casey A. \\ Hughes $^{1}$, Nathalie Quach ${ }^{1}$, Megan Keniry ${ }^{3}$, and James M. Bullard ${ }^{1, *}$ \\ ${ }^{1}$ Chemistry Department, The University of Texas-RGV, 1201 W. University Drive, Edinburg, TX \\ $78541 ;{ }^{2}$ Current address: Department of Pharmacology and Toxicology, College of Pharmacy, \\ The University of Arizona, Tucson, Arizona 85721 and ${ }^{3}$ Biology Department, The University of \\ Texas-RGV, 1201 W. University Drive, Edinburg, TX 78541
}

\begin{abstract}
Background: Pseudomonas aeruginosa is an opportunistic multi-drug resistance pathogen implicated as the causative agent in a high-percentage of nosocomial and community acquired bacterial infections. The gene encoding leucyl-tRNA synthetase (LeuRS) from $P$. aeruginosa was overexpressed in Escherichia coli and the resulting protein was characterized.
\end{abstract}

Methods: LeuRS was kinetically evaluated and the $K_{\mathrm{M}}$ values for interactions with leucine, ATP and tRNA were $6.5,330$, and $3.0 \mu \mathrm{M}$, respectively. LeuRS was developed into a screening platform using scintillation proximity assay (SPA) technology and used to screen over 2000 synthetic and natural chemical compounds.

\footnotetext{
*Address correspondence to this author at the Chemistry Department, ESCNE. 3.320, The University of Texas-RGV, $1201 \mathrm{~W}$. University Drive, Edinburg, TX 78541; Tel: 956-665-2950; Mobile: 303-775-5100; Fax: 956665-5006; james.bullard@utrgv.edu; jmbullard.wa@gmail.com.

DISCLOSURE

The authors disclose that portions of the "Methods and Materials" section was previously described in the following articles and redescribed here for clarity and descriptive purposes.

- Discovery and characterization of chemical compounds that inhibit the function of aspartyl-tRNA synthetase from Pseudomonas aeruginosa. SLAS Discov 2018; 23: 294-301.

- Identification and characterization of a chemical compound that inhibits methionyl-tRNA synthetase from Pseudomonas aeruginosa. Current Drug Discovery Technologies 2017; 14: 156-168.

ETHICS APPROVAL AND CONSENT TO PARTICIPATE

Not applicable.

HUMAN AND ANIMAL RIGHTS

No Animals/Humans were used for studies that are the basis of this research.

CONSENT FOR PUBLICATION

Not applicable.

CONFLICT OF INTEREST

The authors declare no conflict of interest, financial or otherwise.

SUPPLEMENTARY MATERIAL

Supplementary material is available on the publisher's website along with the published article.

Publisher's Disclaimer: DISCLAIMER: The above article has been published in Epub (ahead of print) on the basis of the materials provided by the author. The Editorial Department reserves the right to make minor modifications for further improvement of the manuscript.
} 
Results: The initial screen resulted in the identification of two inhibitory compounds, BT03C09 and BT03E07. $\mathrm{IC}_{50}$ s against LeuRS observed for BT03C09 and BT03E07 were 23 and $15 \mu \mathrm{M}$, respectively. The minimum inhibitory concentrations (MIC) were determined against nine clinically relevant bacterial strains. In time-kill kinetic analysis, BT03C09 was observed to inhibit bacterial growth in a bacteriostatic manner, while BT03E07 acted as a bactericidal agent. Neither compound competed with leucine or ATP for binding LeuRS. Limited inhibition was observed in aminoacylation assays with the human mitochondrial form of LeuRS, however when tested in cultures of human cell line, BT03C09 was toxic at all concentration whereas BT03E07 only showed toxic effects at elevated concentrations.

Conclusion: Two compounds were identified as inhibitors of LeuRS in a screen of over 2000 natural and synthetic compounds. After characterization one compound (BT03E07) exhibited broad spectrum antibacterial activity while maintaining low toxicity against human mitochondrial LeuRS as well as against human cell cultures.

\section{Keywords}

leucyl-tRNA synthetase; protein synthesis; Pseudomonas aeruginosa; drug discovery; antibiotics

\section{INTRODUCTION}

Bacterial resistance to the current armory of antibiotic agents is a major problem facing the health related industry worldwide. Bacteria have intrinsic genetic mechanisms for the development of resistance against antibacterials and may demonstrate natural resistance to certain types of antibiotics. However, the ability to become resistant, due to drug induced genetic mutation or by genetic information taken up from other pathogens, to multiple antibacterial compounds has become a pressing issue. These multidrug-resistant (MDR) bacteria have become a major threat during treatment of nosocomial and community acquired infections as well as their involvement in chronic infections. MDR strains have been associated with a higher rate of mortality, secondary bacteremia, increased length of hospital stays, and a large increase in cost of care [1]. Pseudomonas aeruginosa is an opportunistic Gram-negative bacteria that is a primary cause of nosocomial infections and the leading cause of mortality in cystic fibrosis patients. $P$. aeruginosa has the ability to acquire resistance against all groups of antimicrobial agents and multidrug resistance is common and increasing in this organism making treatment of infections both difficult and expensive. Because of the capacity for developing resistance, $P$. aeruginosa has become a member of an elevated group of pathogenic MDR bacteria referred to as "superbugs" [2].

Leucyl-tRNA synthetase (LeuRS), encoded by the leuS gene, catalyzes the reaction in which the enzyme reacts with three substrates (ATP, leucine, and tRNA ${ }^{\text {Leu }}$ ) resulting in the aminoacylation of tRNA ${ }^{\text {Leu }}$. LeuRS is a class I aminoacyltRNA synthetase (aaRS) which is characterized by two structural motifs (HIGH and KMSKS) forming the active site of the Rossman fold catalytic domain [3]. LeuRS is further grouped along with isoleucyl-, valyl-, methionyl-, cysteinyl- and arginyl-tRNA synthetases (IleRS, ValRS, MetRS, CysRS and ArgRS) into subclass Ia based on sequence conservation. In bacteria, LeuRS contains an error-correction function (editing domain) to ensure cognate amino acid specificity during the aminoacylation process. The editing occurs either at the pre-transfer state in which the 
mis-activated amino acid (adenylate) is hydrolyzed, or at the post-transfer state in which the amino acid of the mischarged tRNA is hydrolyzed [4]. This same proofreading process is employed by both IleRS and ValRS. Alternatively, MetRS, ArgRS and CysRS are able to specifically bind cognate amino acids using an induced fit mechanism [5], a specific $\mathrm{H}$ bonding network [6], or specific interactions with a metal ion [7], respectively. Another variation of the specificity of the aminoacylation reaction occurs in binding of the cognate tRNA. Selection of the cognate tRNA by most aaRS enzymes depends on the anticodon as the primary element of recognition. However, tRNA ${ }^{\text {Leu }}$ (which has six anticodon isoacceptors) recognition by LeuRS is not determined by interaction with the anticodon, instead LeuRS recognizes the discriminator base, A73, and regions of the D-arm (particularly at positions U8 and A14) [8].

LeuRS from $P$. aeruginosa was cloned and purified and the kinetic parameters $\left(K_{\mathrm{M}}, \mathrm{V}_{\max }\right.$ and the observed turnover number, $k_{\text {cat }}{ }^{\text {obs }}$ ) for interaction with its substrates were experimentally determined. Additionally, LeuRS was developed into a screening platform using scintillation proximity assay (SPA) technology [9] and used to screen over 2000 natural and synthetic compounds for inhibition of activity. Two compounds were identified that inhibited the activity of LeuRS. These compounds were further characterized for their ability to inhibit both the enzymatic activity of LeuRS and growth of a panel of problematic pathogens in culture. The potential mechanism of inhibition, relative to substrate binding, was also assessed, as well as the global mode of action of inhibition of growing cultures of bacteria. To determine the potential for development as an antibacterial agent, the ability of the compounds to inhibit the activity of the human mitochondrial form of LeuRS (hmLeuRS) and toxicity to human cell cultures were also analyzed.

\section{METHODS AND MATERIALS}

\subsection{Materials}

Oligonucleotides were from Integrated DNA Technologies (Coralville, IA). All chemicals were from Fisher Scientific (Pittsburg, PA). DNA was sequenced by Functional Biosciences (Madison, WI). Radioactive isotopes were from PerkinElmer (Waltham, MA). tRNA was from E. coli MRE 600 (Roche Diagnostics, Mannheim, Germany). The E. coli tolC mutant strain, $P$. aeruginosa PAO200 (efflux pump mutant) and $P$. aeruginosa hypersensitive strain $\left(\mathrm{ATCC}^{\circledR} 35151^{\mathrm{TM}}\right.$ ) were a kind gift from Urs Ochsner (Crestone Pharma-Boulder, CO). All other bacteria were from American Type Culture Collection (ATCC) (Manassas, VA). The natural product libraries were from MicroSource Discovery Systems, Inc. (Gaylordsville, CT) and Prestwick Chemical, Inc. (Strasbourg-Illkirch, France), and the synthetic compound library was from TimTec LLC (Newark, DE). Compounds stocks were dissolved in dimethyl sulfoxide (DMSO) to a concentration of $10 \mathrm{mM}$, stored at $-20^{\circ} \mathrm{C}$ and thawed immediately before analysis. The compounds have an average purity of $95 \%$, and the minimum purity is at least $90 \%$.

\subsection{Gel Electrophoresis and Protein Analysis}

SDS-PAGE was performed using 4-12\% polyacrylamide pre-cast gels (Novex NuPAGE; Invitrogen) with MOPS running buffer (Invitrogen). EZ-Run ${ }^{\mathrm{TM}} \operatorname{Rec}$ Protein Ladder was 
from Fisher Scientific. Gels were stained with Simply Blue Safe Stain (Invitrogen). Protein concentrations were determined using Coomassie Protein Assay Reagent (Thermo Scientific) with bovine serum albumin as the standard.

\subsection{Cloning and Purification of $P$. aeruginosa LeuRS}

The gene encoding $P$. aeruginosa LeuRS was obtained through PCR amplification (MJ Mini Thermo Cycler, BioRad, Hercules, CA) using $P$. aeruginosa PAO1 (ATCC 47085) genomic DNA as a substrate. A forward primer (5'-gaacgctagccacgagcaatatcagccact-3'), designed to add an Nhel restriction site to the 5' end of the gene, and a reverse primer (5'ggataagctttcagttggcgacgatgttg $-3^{\prime}$ ), which was designed to add a HindIII restriction site to the 3' end of the gene, were used in PCR. The PCR product was inserted into a pET-28b(+) plasmid (Novagen) digested with $N$ hel/HindIII. This resulted in the gene, encoding $P$. aeruginosa LeuRS, fused to an upstream region encoding six histidine residues. The recombinant plasmid was transformed into E. coli Rosetta 2(DE3) Singles Competent Cells (EMD Millipore, Danvers, MA). Bacterial cultures were grown, expression of the target protein induced and $P$. aeruginosa LeuRS was purified as described [10].

\subsection{ATP: $P P_{\mathrm{i}}$ Exchange Reactions}

ATP:PP ${ }_{\mathrm{i}}$ exchange reactions $(100 \mu \mathrm{l})$ were carried out at $37{ }^{\circ} \mathrm{C}$ for $20 \mathrm{~min}$ in $50 \mathrm{mM}$ Tris$\mathrm{HCl}$ (pH 7.5), $10 \mathrm{mM} \mathrm{KF}, 8 \mathrm{mM} \mathrm{MgOAc}, 1 \mathrm{mM}$ dithiothreitol (dTt), $2 \mathrm{mM}[32 \mathrm{P}] \mathrm{PP}_{\mathrm{i}}(50$ $\mathrm{cpm} / \mathrm{pmol}$ ) and $0.035 \mu \mathrm{M}$ of $P$. aeruginosa LeuRS as previously described [9]. When the concentration of leucine (Leu) was varied $(1,2.5,5,10,20,25,50,100 \mu \mathrm{M})$, the concentration of ATP was held constant at $2 \mathrm{mM}$ and when the concentration of ATP was varied $(100,150,200,300,400,500,600$ and $750 \mu \mathrm{M})$, the concentration of Leu was held constant at $2 \mathrm{mM}$. The reactions were stopped at 1,2,3,4, and 5 min time points. The $K_{\mathrm{M}}$, $\mathrm{V}_{\text {max }}$ and the $k_{\mathrm{cat}}{ }^{\text {obs }}$ for the interactions of $P$. aeruginosa LeuRS with ATP and leucine were determined by plotting the initial velocities for exchange of $\mathrm{PP}_{\mathrm{i}}$ at each concentration of the varied substrate, and fitting these data to the Michaelis-Menten steady-state model using XLfit (IDBS).

\subsection{Timed Aminoacylation Assays}

Aminoacylation was measured using filter binding assays $(50 \mu \mathrm{L})$ containing $50 \mathrm{mM}$ Tris$\mathrm{HCl}$ (pH 7.5), $7.5 \mathrm{mM} \mathrm{MgCl} 2,2.5 \mathrm{mM}$ ATP, $1 \mathrm{mM}$ dithiothreitol (DTT), $75 \mu \mathrm{M}\left[{ }^{3} \mathrm{H}\right] \mathrm{Leu}$, and $0.5 \mu \mathrm{M}$ P. aeruginosa LeuRS, as previously described [9]. The tRNA ${ }^{\text {Leu }}$ concentrations were varied between 1 and $10 \mu \mathrm{M}$. Assays were stopped at time intervals between 1 and 5 min. Initial velocities for aminoacylation were calculated for all tRNA concentrations and the data were fit to the Michaelis-Menten steady-state model using XLfit (IDBS) to determine the kinetic parameters $\left(K_{\mathrm{M}}, \mathrm{V}_{\max }\right.$ and $\left.k_{\text {cat }}{ }^{\text {obs }}\right)$.

\subsection{Chemical Compound Screening}

In the screening of chemical compound libraries for inhibitors of activity, tRNA aminoacylation was monitored using a scintillation proximity assay (SPA) as previously described [9]. The screening reactions were in 96-well microtiter plates (Costar). Compounds were dissolved in 100\% DMSO and the final concentration of compounds in the 
screening assay was $132 \mu \mathrm{M}$. Briefly, $2 \mu \mathrm{l}$ of compound ( $3.3 \mathrm{mM}$ ) was mixed with $33 \mu \mathrm{l}$ of the protein/substrate mix described above for the aminoacylation assay (minus tRNA). The concentration of $P$. aeruginosa LeuRS in the screening assays was set at $0.1 \mu \mathrm{M}$. Positive control reactions contained only DMSO $(2 \mu \mathrm{l})$ with no compound and negative control reactions contained $2 \mu \mathrm{l}$ EDTA $(0.5 \mathrm{M})$. This mixture was incubated at ambient temperature for $15 \mathrm{~min}$ and then reactions were started by the addition of $15 \mu \mathrm{l}$. coli tRNA ( $40 \mu \mathrm{M}$ total tRNA or $3.5 \mu \mathrm{M}$ tRNA ${ }^{\mathrm{Leu}}$ ), followed by incubation for $60 \mathrm{~min}$ at $37^{\circ} \mathrm{C}$. Reactions were stopped by the addition of $5 \mu \mathrm{l}$ of $0.5 \mathrm{M}$ EDTA. $400 \mu \mathrm{g}$ of yttrium silicate (Ysi) poly-Llysine coated SPA beads (Perkin-Elmer) in $150 \mu \mathrm{l}$ of $300 \mathrm{mM}$ citric acid were added and allowed to incubate at room temperature for $1 \mathrm{~h}$. The plates were analyzed using a 1450 Microbeta (Jet) liquid scintillation/luminescent counter (Wallac). For $\mathrm{IC}_{50}$ determination, assays were as described above with the test compounds serially diluted from $200 \mu \mathrm{M}$ to 0.4 $\mu \mathrm{M}$.

\subsection{Microbiological Assays}

Minimum inhibitory concentrations (MICs) were determined using the broth microdilution method performed in 96-well microtiter plates according to the Clinical and Laboratory Standards Institute (CLSI, formerly NCCLS) guideline M7-A7 [11]. MIC values were determined for E. coli (ATCC $\left.{ }^{\circledR} 25922^{\mathrm{TM}}\right)$, E. coli tolC mutant (W4573:tolC::Tn 10), Enterococcus faecalis (ATCC ${ }^{\circledR} 29212^{\mathrm{TM}}$ ), Haemophilus influenzae (ATCC ${ }^{\circledR} 49766^{\mathrm{TM}}$ ), $P$. aeruginosa (ATCC ${ }^{\circledR} 47085^{\mathrm{TM}}$ ), P. aeruginosa PAO200 (efflux pump mutant), P. aeruginosa hypersensitive strain $\left(\right.$ ATCC $^{\circledR} 35151^{\mathrm{TM}}$ ), Staphylococcus aureus $\left(\right.$ ATCC $^{\circledR} 29213^{\mathrm{TM}}$ ), and Streptococcus pneumonia $\left(\right.$ ATCC $^{\circledR} 49619^{\text {TM}}$ ).

Time-kill studies were performed using $E$. faecalis and the E. coli tolC mutant strain as previously described [12], according to the CLSI document M26-A [13]. Growth media was Brain Heart Infusion for E. faecalis and Tryptic Soy Broth for the E. coli tolC mutant (Becton, Dickinson and Company). These same growth media were used in MIC and timekill studies.

\subsection{Human Mitochondrial LeuRS Assays}

Assays were carried out to test the inhibitory effect of compounds on the activity of human mitochondrial LeuRS (hmLeuRS). Human mitochondrial LeuRS was prepared as described [14]. The assay mix $(50 \mu \mathrm{l})$ contained $50 \mathrm{mM}$ Tris- $\mathrm{HCl}(\mathrm{pH} 7.5), 5 \mathrm{mM} \mathrm{MgOAc}, 2.5 \mathrm{mM}$ ATP, $1 \mathrm{mM}$ DTT, $50 \mu \mathrm{M}\left[{ }^{3} \mathrm{H}\right] \mathrm{Leu}$, and $0.075 \mu \mathrm{M}$ hmLeuRS. The mix was incubated for 15 min with serial dilutions of compound ( 200 to $0.4 \mu \mathrm{M}$ ), the reaction was then initiated by addition of $E$. coli tRNA ${ }^{\text {Leu }}(2.5 \mu \mathrm{M})$. The reaction was stopped by diluting into $3 \mathrm{ml}$ of icecold 5\% TCA and filtering through glass fiber filters as described [9].

\subsection{In Vitro Cytotoxicity Test}

To determine the effect of a hit compound on the growth of human cell cultures, in vitro cytotoxicity testing was carried out as described using human embryonic kidney 293 cells (HEK293)[15]. The Trevigen TACS ${ }^{\circledR}$ MTT (3-(4,5-Dimethylthiazol-2-yl)-2,5Diphenyltetrazolium Bromide) Cell Proliferation Assay Kit (Gaithersburg, MD) was used to analyze the impact of the hit compound on human cell proliferation and/or viability. The 
assays were carried out in triplicate. The control staurosporine was serially diluted in assays from 1 to $0.001 \mu \mathrm{g} / \mathrm{ml}$ and the hit compound was tested in assays ranging from $25 \mu \mathrm{g} / \mathrm{ml}$ to $300 \mu \mathrm{g} / \mathrm{ml}$.

\subsection{Binding Mode Assay}

To determine the mechanism of action of the hit compounds with respect to the substrates, leucine and $\mathrm{ATP}, \mathrm{IC}_{50}$ values were determined using SPAs as described above. Final compound concentrations in the $\mathrm{IC}_{50}$ reactions were serially diluted from 200 to $0.4 \mu \mathrm{M}$. Competition with ATP was determined at 25, 50, 100, 250, 500, $1000 \mu \mathrm{M}$ ATP while the Leu concentration was held constant at $75 \mu \mathrm{M}$. Competition with the amino acid was determined at 25, 50,100,200,300 $\mu \mathrm{M}$ Leu while the ATP concentration was held constant at $2.5 \mathrm{mM}$. Positive controls contained only DMSO $(2 \mu \mathrm{l})$ without compound. Background amounts of free $\left[{ }^{3} \mathrm{H}\right]$ Leu in the absence of LeuRS were insignificant.

\section{RESULTS AND DISCUSSION}

\subsection{Sequence Analysis}

The crystal structure in an apo-form and substrate bound forms have been solved for LeuRS from E. coli [16], and Thermus thermophilus (Tth) [17, 18] as well as the archaeal form from Pyrococcus horikoshii [19]. The amino acid sequence of LeuRS from P. aeruginosa exhibits a high degree of conservation when compared with corresponding enzymes of the $\beta$ - and $\gamma$-subdivisions of the proteobacteria phyla resulting in $70-72 \%$ sequence similarity and $56-61 \%$ sequence identity (Table 1). The overall number of similar/identical amino acids is decreased, but still contains a moderately high degree of conservation when compared with some other bacterial clades. When compared with the human mitochondrial (hmLeuRS) and cytoplasmic (hcLeuRS) forms of LeuRS the conservation is decreased even more. Comparison with hmLeuRS exhibits a $47 \%$ sequence similarity and $33 \%$ sequence identity, however, when compared with hcLeuRS, the conservation is almost nonexistent, with only $22 \%$ sequence similarity and $12 \%$ sequence identity.

P. aeruginosa LeuRS, as with forms from other bacteria, is a large enzyme ( $97.6 \mathrm{kDa})$ with multiple flexible domains. In lieu of a crystal structure of $P$. aeruginosa LeuRS, sequence analysis enables active site structure comparison with that of the homologs from E. coli, and Tth in which the structures have been solved (Fig. 1).

LeuRS binds ATP in an induced-fit mechanism resulting in the movement of the conserved signature catalytic "HIGH" and "KMSKS" motifs toward the amino acid binding site [18]. The amino acid residue Met ${ }^{576}$ stacks on the adenine base and residues $\mathrm{Glu}^{540}, \mathrm{Gln}^{574}$, $\mathrm{Val}^{577}$, and $\mathrm{Met}^{638}$ (Tth numbering) form multiple hydrogen bonds with the ribose and the adenine base of ATP, while $\mathrm{Tyr}^{43}$ and $\mathrm{Arg}^{178}$ hydrogen bond to the a-phosphate. These residues are strictly conserved between the E. coli, Tth and $P$. aeruginosa LeuRS homologs (Fig. 1). Binding of the amino acid in the active site of LeuRS causes only minor perturbation as indicated by the similarity of the apo- and leucine-bound structures [18]. The side-chain of the amino acid is captured in a hydrophobic pocket composed of $\mathrm{Met}^{40}$, $\mathrm{Phe}^{41}$, $\mathrm{Tyr}^{43}, \mathrm{Phe}^{501}, \mathrm{Tyr}^{507}, \mathrm{His}^{541}$ and $\mathrm{His}^{545}$. These residues are strictly conserved between the 
three homologs with the exception that E. coli LeuRS contains a leucine instead of a phenylalanine at position 41 . The a-amino group of leucine forms hydrogen bonds with $\mathrm{Asp}^{80}$ (strictly conserved) while $\mathrm{Phe}^{41}$ and $\mathrm{His}^{541}$ also forms hydrogen bonds with the aamino group and the carbonyl oxygen, respectively.

There are numerous contacts between the amino acid residues contained within LeuRS and different regions of the tRNA. The conserved KMSKS motif makes critical interactions with the 3 ' end of the tRNA during the transfer reaction. In the catalytic active site, the discriminator base A73 is stacked between $\operatorname{Trp}^{223}$ and $\mathrm{Arg}^{416}$ (E. coli numbering) and forms hydrogen bonds with $\mathrm{Arg}^{418}$, while $\mathrm{Glu}^{292}$ forms hydrogen bonds with the phosphate of A73 and the 2' hydroxyl of U72, all strictly conserved [16]. There is an $\mathrm{R}^{416}$ LRDWGVSRQRYWG ${ }^{429}$ motif (Fig. 1) that connects the editing domain to the catalytic domain and may act to position the 3' end of the tRNA into the catalytic active site by making specific hydrogen bonds with the tRNA discriminator base, A73 [17]. This motif contains only mild variations in conservation of amino acids in the aligned sequences. A number of residues in the anti-codon binding domain, in particular the conserved regions from 648-670 and 730-743, make non-specific contacts to the elbow region of tRNA. Also in the elbow region of the tRNA, the tertiary base pair G19-C56 is stabilized by interactions with the conserved residues, $\mathrm{Ile}^{848}, \mathrm{Val}^{850}$, and Leu ${ }^{854}$, of the C-terminal domain. This allows hydrogen bonds to form between this region of the tRNA and LeuRS residues, $\mathrm{Asn}^{856}, \mathrm{Gln}^{805}, \mathrm{Asn}^{807}$, and Gly ${ }^{808}$ [17]. These residues are all strictly conserved between the three forms of LeuRS in Fig. 1.

LeuRS contains distinct aminoacylation and editing active sites separated by $\sim 35 \AA$, a distance in which a charged/mischarged tRNA ${ }^{\text {Leu }}$ must be moved during the proof-reading process. The editing domain, like the catalytic domain contains an active site (hydrolytic) that is composed of two regions. The first region contains a threonine-rich sequence $\mathrm{T}^{247}$ TRPDT and the second contains a $\mathrm{G}^{333} \mathrm{TG}$ motif. The first region is strictly conserved, while in the second region, $P$. aeruginosa LeuRS contains a glutamic acid instead of a threonine at position 334 , indicating that the proof-reading process is likely the same in the three homologs.

Comparison of LeuRS from E. coli, P. aeruginosa, and Tth indicate that each have conserved regions labeled as zinc-binding domains (ZN1 and ZN2). Tth LeuRS contains a zinc-binding knuckles in each domain and in the crystal structure is shown to bind a $\mathrm{Zn}^{2+}$ in each [18]. The E. coli LeuRS does not contain a zinc-binding knuckle in ZN2, however it does contain a partial zinc-binding knuckle in the ZN1 domain. This knuckle contains only three cysteine/ histidine residues as opposed to four, and theoretically allows partial coordination of the $\mathrm{Zn}^{2+}$ when the tRNA is in the catalytic active site, but when in the hydrolytic active site of the editing domain the loosely bound $\mathrm{Zn}^{2+}$ is released [20]. In P. aeruginosa LeuRS, there is no zinc-binding knuckle in the $\mathrm{ZN} 1$ domain, however a complete zinc-binding knuckle exist in ZN2 (Fig. 1). Sequence alignment of the amino acids from LeuRS proteins identified various bacterial clades containing many variations of zinc-binding ligands (Suppl. Fig. S1). Interestingly, $P$. aeruginosa is grouped into the $\gamma$-proteobacteria phyla, however in the alignment of the LeuRS enzymes from this phyla, only $P$. aeruginosa LeuRS does not contain the same zinc-binding knuckle configuration as that observed with LeuRS from $E$. 
coli. Alternatively, the $P$. aeruginosa LeuRS has the same zinc-binding knuckle configuration as observed with LeuRS from bacteria grouped in $\alpha-, \beta-, \delta$-, and $\varepsilon$-proteobacteria phyla.

\subsection{Protein Expression and Characterization}

Leucyl-tRNA synthetase from $P$. aeruginosa was cloned, overexpressed in E. coli and purified to greater than $95 \%$ homogeneity as visualized by SDS-PAGE (Suppl. Fig. S2). In the aminoacylation assay, LeuRS was observed to be active in attaching leucine to the cognate tRNA (Fig. 2A). This reaction is the primary physiological function of an aminoacyl tRNA synthetase and it occurs via two distinct enzymatic steps in which the amino acid substrate is not released from the enzyme. During the first step the enzyme catalyzes the condensation of the amino acid and ATP, forming an aminoacyl adenylate intermediate followed by the release of an inorganic pyrophosphate $\left(\mathrm{PP}_{\mathrm{i}}\right)$. This reaction is reversible in the absence of cognate tRNA and has historically been used to monitor the interaction of the enzyme with the amino acid and ATP using the ATP: $\mathrm{PP}_{\mathrm{i}}$ exchange assay. Using this assay, the kinetic parameters governing the interaction of $P$. aeruginosa LeuRS with ATP and leucine were determined as described under the "Methods and Material" section. To determine the kinetic parameters with respect to ATP, the concentration of leucine was held constant while the concentration of ATP was varied between 100 and $750 \mu \mathrm{M}$. Alternatively, to determine these parameters with respect to leucine, the concentration of ATP was held constant while the concentration of the amino acid was varied between 1 and $10 \mu \mathrm{M}$. The initial velocities were determined at all substrate concentration and fit to the MichaelisMenten steady-state model using XLfit (IDBS) (Fig. 2B-C). The kinetic parameters, $K_{\mathrm{M}}$, $k_{\mathrm{cat}}{ }^{\text {obs }}$, and $k_{\mathrm{cat}}{ }^{\text {obs }} / K_{\mathrm{M}}$, for interaction of $P$. aeruginosa LeuRS with ATP were determined to be $330 \mu \mathrm{M}, 46.9 \mathrm{~s}^{-1}$, and $0.14 \mathrm{~s}^{-1} \mu \mathrm{M}^{-1}$, respectively (Fig. 2E). These parameters for the interaction with leucine were $6.5 \mu \mathrm{M}, 59.4 \mathrm{~s}^{-1}$, and $9.2 \mathrm{~s}^{-1} \mu \mathrm{M}^{-1}$, also respectively. The same kinetic values, $K_{\mathrm{M}}$ and $k_{\text {cat }}$, observed for $E$. coli LeuRS with ATP and leucine were 280 $\mu \mathrm{M} / 3.6 \mathrm{~s}^{-1}$ and $15 \mu \mathrm{M} / 3 \mathrm{~s}^{-1}$, respectively [21].

In the second step of the reaction, leucine is transferred to the acceptor end of the cognate tRNA ${ }^{\text {Leu }}$ and the AMP is released from the adenylate. This step tends to be the rate limiting step and the turnover number for the entire aminoacylation reaction is well below that for formation of the aminoacyl adenylate. The aminoacylation reaction assay was used to determine the kinetic constants governing the attachment of leucine to the cognate tRNA by LeuRS. In these reactions the concentration of leucine and ATP were saturating while tRNA $^{\text {Leu }}$ concentrations was varied between 1 and $10 \mu \mathrm{M}$. The initial velocities were determined and fit to the Michaelis-Menten steady-state model (Fig. 2D) and the $K_{\mathrm{M}}$, $k_{\text {cat }}{ }^{\text {obs }}$, and $k_{\text {cat }}{ }^{\text {ohs }} / K_{\mathrm{M}}$ values for LeuRS interactions with tRNA were determined to be 3 $\mu \mathrm{M}, 0.44 \mathrm{~s}^{-1}$, and $0.15 \mathrm{~s}^{-1} \mu \mathrm{M}^{-1}$, respectively. Corresponding values of the $K_{\mathrm{M}}$ and $k_{\text {cat }}$ for E. coli LeuRS were $1.5 \mu \mathrm{M}$ and $2.9 \mathrm{~s}^{-1}$, respectively.

\subsection{Screening for Chemical Compound Inhibitors of the Activity of P. aeruginosa LeuRS}

The ability of chemical compounds to inhibit the activity of LeuRS in the aminoacylation assay was determined using SPA technology. This assay was used to screen three chemical compound libraries. First, the Prestwick Phytochemical Library collection of 320 natural products, mostly derived from plants. Second, the NatProd Collection from Microsource 
Discovery Systems, composed of 800 natural products including simple and complex oxygen heterocycles, alkaloids, sesquiterpenes, diterpenes, pentacyclic triterpenes, and sterols. Finally, the Anti-infective Library from TimTec LLC containing 890 low molecular weight synthetic compounds with scaffolds based on known anti-bacterial, anti-fungoid, and anti-microbial agents. The chemical compounds $(3.3 \mathrm{mM})$ were dissolved in DMSO and screening reactions ( $50 \mu \mathrm{l})$ contained $2 \mu \mathrm{l}$ of compound resulting in a final compound concentration of $132 \mu \mathrm{M}$. The addition of $2 \mu \mathrm{l}$ of compounds dissolved in DMSO resulted in $4 \%$ DMSO in the reaction. To ensure that DMSO had no effect on the activity of LeuRS, it was titrated into the assay to a final concentration of $10 \%$. There was no decrease in enzymatic activity observed to 10\% DMSO (Suppl. Fig. S3). Screening assays were performed as single point assays, and compounds observed to inhibit at least $50 \%$ of enzymatic activity were confirmed in additional assays performed in triplicate. The initial screen resulted in thirteen confirmed hit compounds. These compounds were analyzed to determine $\mathrm{IC}_{50}$ values and the values ranged between 1.6 and $51 \mu \mathrm{M}$ across all compounds (Suppl. Table S1).

\subsection{Microbiological Assays}

All 13 confirmed hit compounds were tested in broth microdilution assays to determine MIC values. The tests were performed against a panel of nine pathogenic bacteria, including efflux pump mutants of $E$. coli and $P$. aeruginosa and a hypersensitive strain of $P$. aeruginosa (Suppl. Table S1). Of the four natural product compounds identified from the Prestwick collection, only one exhibited promising MIC values. However, this compound BP02E10 (Olivacine) was observed to be active in numerous PubChem bioassays and was the subject of many patent applications and will not be considered further. The six natural products from the Microsource compounds that inhibited the activity of the assay, BM03D02, BM04F03, BM05F04, BM07D08, BM08C09, and BM09J05, were identified as pomiferin, koparin, podophyllin acetate, quercetin, cearoin, and harmine, respectively. These compounds also were active in numerous PubChem bioassays and were classified as being carcinogens, hallucinogens, caustic agents or toxic to humans and will not be considered further. The synthetic compound BT04F03 exhibited the lowest $\mathrm{IC}_{50}$, however very high MIC values were observed. The fact that this compound has a molecular mass of near $800 \mathrm{kDa}$ and numerous hydrogen bond donors and acceptors and 15 rotatable bonds makes it a poor candidate for drug development since it violates Lipinski's rule of five. Therefore, this compound will not be considered further. BT03C09 and BT03E07 (Fig. 3A-B) were observed to have moderate MICs against Gram-positive bacteria, and against the Gramnegative $H$. influenzae as well as the tolC mutant strain of $E$. coli, however the compounds were ineffective against any form of $P$. aeruginosa (Table 2). These two compounds were further analyzed for their ability to inhibit enzymatic activity, including that of the human mitochondrial form of LeuRS, global mode of anti-bacterial activity, mechanism of inhibition and for toxicity in human cell cultures.

\subsection{Analysis of BT03E07 and BT03C09}

The $\mathrm{IC}_{50}$ values of $\mathrm{BT} 03 \mathrm{C} 09$ and $\mathrm{BT} 03 \mathrm{E} 07$ for inhibition of the aminoacylation activity of LeuRS were determined using SPAs. In these assays, the compounds were serially diluted 
from $200 \mu \mathrm{M}$ to $0.4 \mu \mathrm{M}$ (Fig. 4A-B). BT03C09 and BT03E07 were observed to inhibit the activity of $P$. aeruginosa LeuRS with $\mathrm{IC}_{50}$ values of 23 and $15 \mu \mathrm{M}$, respectively.

To determine the global mode of inhibition of the growth of bacterial cultures, the two compounds were tested in time-kill kinetic assays. The compounds were tested at concentrations of four times the MIC and at time points between 0 and 24 hours against cultures of E. faecalis and the E. coli to/C mutant stain (Fig. 4C-D). BT03C09 was shown to be bacteriostatic against the Gram-negative and Gram-positive pathogens tested, it had constant growth but a decrease in colony forming units (CFU) of 1 to $3 \log 10$ compared to the control during the time course tested. Alternatively, BT03E07 exhibited a bactericidal mode of action and inhibited bacterial growth by killing both E. faecalis and the E. coli efflux pump mutant strain.

The binding sites of both ATP and leucine are located in the active region of the catalytic domain of LeuRS. The small molecules identified are similar in molecular mass to that of both the amino acid and ATP, therefore, it was important to test whether they interfered with substrate binding as a possible mechanism of inhibition. ATP utilization as a substrate is prevalent in both bacterial and eukaryotic cells, therefore inhibition resulting from ATP competition would decrease the utility of the compound as a potential drug candidate. However, LeuRS uniquely binds leucine, and competitive inhibition with the amino acid could be very specific. Both compounds were tested in competition assays with varying amounts of ATP or leucine (Suppl. Fig. S6). In these assays the $\mathrm{IC}_{50} \mathrm{~s}$ for both BT03C09 and BT03E07 remained constant at all concentrations of both ATP and leucine which is characteristic of a noncompetitive inhibitor. We conclude that both compounds inhibit the function of LeuRS by a mechanism different than direct competition with either substrate in the active site. It is possible that the compounds could interfere with binding of the tRNA or bind elsewhere on the enzyme possibly inhibiting function by an allosteric mechanism. However to better understand the mechanism of action of enzymatic inhibition future structural studies will be required.

Antibiotic therapies targeting bacterial LeuRS could potentially be toxic to mammalian cells given that eukaryotic cells contain both cytoplasmic and mitochondria forms of LeuRS and each share limited homology with bacteria LeuRS. Assays were carried out to test the inhibitory effect of BT03 09 and BT03E07 on the activity of the human mitochondrial form of LeuRS (hmLeuRS). In dose response assays, in which the test compounds were tested for inhibitory activity against hmLeuRS, the compounds were serially diluted from 200 to 0.4 $\mu \mathrm{M}$. In these assays, the $\mathrm{IC}_{50}$ values were observed to be 55 and $178 \mu \mathrm{M}$ for BT03C09 and BT03E07, respectively (Fig. 5A-B).

Predicting chemical toxicity using human cell systems is a viable first step in drug discovery, therefore the inhibition of human cytoplasmic LeuRS (hcLeuRS) or another potential target in human cells was tested for by determining cytotoxicity in human embryonic kidney 293 (HEK-293) cell cultures using the Trevigen TACS ${ }^{\circledR}$ MTT Cell Proliferation Assay Kit. MTT assays were performed at compound concentrations between 25 and $300 \mu \mathrm{g} / \mathrm{ml}$ for 24 hours. BT03C09 was observed to be toxic to cell growth at all concentrations tested. BT03E07 exhibited a $\mathrm{CC}_{50}$ of near $80 \mu \mathrm{g} / \mathrm{ml}$ (Fig. 5C). As a comparator, staurosporine, a potent 
inhibitor of human cell cultures [22], was used in the studies. Staurosporine was observed to inhibit cell growth with a $\mathrm{CC}_{50}$ of $0.003 \mu \mathrm{g} / \mathrm{ml}$ (Fig. 5D).

\section{CONCLUSION}

We live in a world in which bacterial resistance has become wide-spread, and constitutes a threat to modern health care. An especially noteworthy development is the appearance of bacterial strains, such as $P$. aeruginosa, that are resistant to all approved antibacterials [23]. These findings increase the impetus for discovery of new and different types of antibiotics that can be made available for combating the rising number of resistant pathogenic bacteria. The aminoacyl-tRNA synthetases are vital for cell growth in all organisms, yet bacterial forms are divergent in amino acid primary structure conservation from that of eukaryotic counterparts, making them ideal targets for development of new antibacterial agents. The amino acid sequence of $P$. aeruginosa LeuRS, when compared to homologs from other members of the $\beta$ - and $\gamma$-proteobacteria were very similar (greater than $70 \%$ sequence conservation). Even when compared to LeuRS from other groups of bacteria, a moderately high degree (above 50\%) of sequence conservatism was observed (Table 1). This indicates that an inhibitor of bacterial LeuRS may have broad spectrum activity. The crystal structures for many of the aminoacyltRNA synthetases have been solved which allows identification and comparison of regions critical for enzymatic function. The structures of E. coli and Tth LeuRS were previously solved and when the amino acid sequence from these enzymes were compared with that of $P$. aeruginosa LeuRS, the critical amino acid residues were found to be strictly conserved indicating likely conservation of structure as well as function.

Recently, several attempts have been made to identify inhibitors of bacterial LeuRS. A group of compounds, aminomethylbenzoxaboroles, coming out of research primarily at Anacor Pharmaceuticals with later work at GlaxoSmithKline resulted in a lead compound, AN3365, which targeted LeuRS and displayed good antibacterial activity against Gram-negative pathogens [24]. Initially, in clinical trials, there was rapid resistance issues with this compound when administrated alone, however it is now being tested in combination therapies with some success [25]. Research using receptor-based virtual screening methods, conducted at the National Academy of Science of Ukraine in conjunction with Otava Chemicals, identified derivatives of two compound series, 5-phenylamino-2H[1,2,4]triazin-3-one and $N$-Benzylidene- $N$-thiazol-2-ylhydrazine [26]. These compounds have shown promising pre-clinical activity against Mycobacterium tuberculosis.

In the present work, $P$. aeruginosa LeuRS was developed into a screening platform based on SPA technology and used to screen over 2000 compounds for inhibitors of aminoacylation activity. The screening assays were robust and resulted in $\mathrm{Z}$ ' and $\mathrm{Z}$ factors of approximately 0.53 and 0.47 , respectively, across all plates. The signal to background ratio of the DMSO positive controls to the EDTA negative controls was approximately 4.4:1. In the initial screen, thirteen compounds were identified and confirmed as hit compounds. After structure analysis, MIC results and PubChem bioassays comparison, two compounds, BT03C09 and BT03E07, were selected for further analysis. BT03C09 (PubChem Compound Database; CID 1079381) and BT03E07 (PubChem Compound Database; CID 5295792) have no bioassay information available (https://pubchem.ncbi.nlm.nih.gov/compound/, accessed 
April. 12, 2018). BT03C09 is composed of a sulfone group connecting a benzo[cd]indole and an aminonaphtho oxa-thiol (Fig. 3A). Certain sulfa drugs, including sulfanilamide and dapsone, contain a sulfonyl functional group, either attached to the main structure or acting as the central connecting region of a molecule, respectively. BT03E07 is composed of a methoxy-4H-carboline with an attached nitro-furan (Fig. 3B). Nitro-furan moieties are contained within a group of synthetic compounds that have been shown to have broad spectrum antimicrobial activity against Gram-positive organisms.

The expected result of inhibition of the aminoacylation activity of a bacterial aaRS would be static growth of the bacteria population. This occurs because inhibition of an aaRS mimics amino acid starvation in protein biosynthesis which would eliciting the stringent response resulting in bacteriostatic inhibition of growth, but not necessarily killing of bacteria. In time-kill experiments, BT03C09 was observed to inhibit both Gram-positive and Gramnegative bacterial growth in a bacteriostatic manner. Alternatively, BT03E07 exhibited bactericidal inhibition by killing the bacteria. The bactericidal form of inhibition observed with BT03E07 may be due to inhibition of secondary roles and functions as well as inhibition of the aminoacylation function. Recently, many secondary roles have been observed for many members of the aaRS group of enzymes [27]. These secondary functions have primarily been documented for eukaryotic aaRS enzymes, however, this has also been seen with some bacterial and mitochondrial aaRS proteins. The mitochondrial form of LeuRS has been shown to possess a function in RNA splicing activity [28] as well as the ability to rescue defects in cognate and non-cognate tRNA [29]. There may likely be vital secondary roles played by LeuRS in bacteria that are not understood but are potentially effected by BT03E07.

Even though there are significant differences in the amino acid sequence of bacterial aaRS enzymes compared to that of eukaryotic homologs, there may be enough structural similarity in the active site regions for compounds that inhibit the bacterial enzyme to effect the eukaryotic enzyme. This becomes increasingly important relative to enzymes contained within the original eukaryotic endosymbiont, the mitochondria. To test for this possibility, we determined the $\mathrm{IC}_{50}$ for inhibition of hmLeuRS by both BT03C09 and BT03E07. The $\mathrm{IC}_{50}$ of BT03E07 against hmLeuRS was $178 \mu \mathrm{M}$, which is significantly higher than that observed with $P$. aeruginosa LeuRS $(15 \mu \mathrm{M})$. A 12:1 inhibition ratio between the mitochondrial and bacterial enzymes is an acceptable starting place for development of a lead series of antibacterial compounds. The $\mathrm{IC}_{50}$ of $\mathrm{BT} 03 \mathrm{C} 09$ was $55 \mu \mathrm{M}$, which is only twice as high as that observed with $P$. aeruginosa LeuRS $(23 \mu \mathrm{M})$. This level of inhibition of the mitochondrial LeuRS reduces the attractiveness of this compound as an antibacterial agent. To further test for the effect of the compounds on eukaryotic cell growth, the compounds were assayed for toxicity in human cell cultures. BT03C09 inhibited human cell growth at all concentrations tested, confirming the lack of usefulness as an antibacterial agent. Additional research is required, however this compound may potentially be of use in cancer research based on its ability to inhibit human mtLeuRS as well as human cells in culture. BT03E07, when tested against human cell cultures, exhibited a $\mathrm{CC}_{50}$ of near 80 $\mu \mathrm{g} / \mathrm{ml}$ which appears problematic, however when compared to other antibiotics, such as erythromycin and tetracycline, the toxicity profiles were similar [30]. Also, the toxic 
concentration is $\sim 25,500$-fold higher than the control, staurosporine (Fig. 5D), which supports its potential utility as a lead candidate in antibacterial drug development.

\section{Supplementary Material}

Refer to Web version on PubMed Central for supplementary material.

\section{ACKNOWLEDGEMENTS}

The authors are grateful for the financial support provided by the National Institutes of Health (grant number: 1SC3GM098173). The contents of this article are solely the responsibility of the authors and do not necessarily represent the official views of the National Institutes of Health. A portion of graduate student support was from a departmental grant from the Robert A. Welch Foundation (Grant No. BG-0017). Partial undergraduate support was from an NIH UTRGV RISE program, grant \# 1R25GM100866.

\section{ABBREVIATIONS}

$\begin{array}{ll}\text { aaRS } & \text { aminoacyl-tRNA synthetase } \\ \text { Leu } & \text { leucine } \\ \text { DTT } & \text { dithiothreitol } \\ \text { MgOAc } & \text { magnesium acetate } \\ \text { KF } & \text { potassium floride } \\ \text { DMSO } & \text { dimethyl sulfoxide } \\ \text { ATP } & \text { adenosine triphosphate } \\ \text { MOPS } & \text { 3-(N-morpholino)propanesulfonic acid } \\ \text { HEPES } & \text { 4-(2-hydroxyethyl)-1-piperazine ethane sulfonic acid } \\ \text { EDTA } & \text { ethylene diamine tetraacetic acid } \\ \text { SPA } & \text { scintillation proximity assay }\end{array}$

\section{REFERENCES}

[1]. Giamarellou H, Kanellakopoulou K. Current therapies for Pseudomonas aeruginosa. Crit Care Clin 2008; 24: 61-78.

[2]. Breidenstein EB, Fuente-Nunez C, Hancock RE. Pseudomonas aeruginosa: all roads lead to resistance. Trends Microbiol 2011; 19: 419-26. [PubMed: 21664819]

[3]. Eriani G, Delarue M, Poch O, Gangloff J, Moras D. Partition of tRNA synthetases into two classes based on mutually exclusive sets of sequence motifs. Nature 1990; 347: 203-6. [PubMed: 2203971]

[4]. Jakubowski H Quality control in tRNA charging. Wiley Interdiscip Rev RNA 2012; 3: 295-310. [PubMed: 22095844]

[5]. Crepin T, Schmitt E, Mechulam Y, et al. Use of analogues of methionine and methionyl adenylate to sample conformational changes during catalysis in Escherichia coli methionyl-tRNA synthetase. J Mol Biol 2003; 332: 59-72. [PubMed: 12946347]

[6]. Cavarelli J, Delagoutte B, Eriani G, Gangloff J, Moras D. L-arginine recognition by yeast arginyltRNA synthetase. EMBO J 1998; 17: 5438-48. [PubMed: 9736621] 
[7]. Newberry KJ, Hou YM, Perona JJ. Structural origins of amino acid selection without editing by cysteinyl-tRNA synthetase. EMBO J 2002; 21: 2778-87. [PubMed: 12032090]

[8]. Asahara H, Himeno H, Tamura K, Hasegawa T, Watanabe K, Shimizu M. Recognition nucleotides of Escherichia coli tRNA(Leu) and its elements facilitating discrimination from tRNASer and tRNA(Tyr). J Mol Biol 1993; 231: 219-29. [PubMed: 8510145]

[9]. Hu Y, Guerrero E, Keniry M, Manrrique J, Bullard JM. Identification of chemical compounds that inhibit the function of glutamyl-tRNA synthetase from Pseudomonas aeruginosa. Journal of Biomolecular Screening 2015; 20: 1160-70. [PubMed: 26116192]

[10]. Corona A, Palmer SO, Zamacona R, Mendez B, Dean FB, Bullard JM. Discovery and characterization of chemical compounds that inhibit the function of aspartyl-tRNA synthetase from Pseudomonas aeruginosa. SLAS Discov 2018; 23: 294-301. [PubMed: 29186665]

[11]. Methods for dilution antimicrobial susceptibility test for bacteria that grow aerobically: Approved guidelines M7-A7. CLSI, Wayne PA M7-A7. 2006 Clinical and Laboratory Standards Institute.

[12]. Ribble W, Hill WE, Ochsner UA, Jarvis TC, Guiles JW, Bullard JM. Discovery and analysis of 4H-pyridopyrimidines, a class of selective bacterial protein synthesis inhibitors. Antimicrob Agents Chemother 2010; 54: 4648-57. [PubMed: 20696870]

[13]. Methods for determining bactericidal activity of antimicrobial agents: approved guideline M26A. CLSI, Wayne, PA M26-A. 2002 Clinical and Laboratory Standards Institute.

[14]. Bullard JM, Cai YC, Spremulli LL. Expression and characterization of the human mitochondrial leucyl-tRNA synthetase. Biochim Biophys Acta 2000; 1490: 245-58. [PubMed: 10684970]

[15]. Hu Y, Keniry M, Palmer SO, Bullard JM. Discovery and analysis of natural product compounds inhibiting protein synthesis in Pseudomonas aeruginosa. Antimicrob Agents Chemother 2016; 60: 4820-9. [PubMed: 27246774]

[16]. Palencia A, Crepin T, Vu MT, Lincecum TL, Jr., Martinis SA, Cusack S. Structural dynamics of the aminoacylation and proofreading functional cycle of bacterial leucyl-tRNA synthetase. Nat Struct Mol Biol 2012; 19: 677-84. [PubMed: 22683997]

[17]. Tukalo M, Yaremchuk A, Fukunaga R, Yokoyama S, Cusack S. The crystal structure of leucyltRNA synthetase complexed with tRNALeu in the post-transfer-editing conformation. Nat Struct Mol Biol 2005; 12: 923-30. [PubMed: 16155583]

[18]. Cusack S, Yaremchuk A, Tukalo M. The $2 \AA$ crystal structure of leucyl-tRNA synthetase and its complex with a leucyl-adenylate analogue. EMBO J 2000; 19: 2351-61. [PubMed: 10811626]

[19]. Fukunaga R, Yokoyama S. Aminoacylation complex structures of leucyl-tRNA synthetase and tRNALeu reveal two modes of discriminator-base recognition. Nat Struct Mol Biol 2005; 12 : 915-22. [PubMed: 16155584]

[20]. Kumar M, Kumar SA, Dimkovikj A, et al. Zinc is the molecular "switch" that controls the catalytic cycle of bacterial leucyl-tRNA synthetase. J Inorg Biochem 2015; 142: 59-67. [PubMed: 25450019]

[21]. Chen JF, Guo NN, Li T, Wang ED, Wang YL. CP1 domain in Escherichia coli leucyl-tRNA synthetase is crucial for its editing function. Biochemistry 2000; 39: 6726-31. [PubMed: 10828991]

[22]. Schnier JB, Gadbois DM, Nishi K, Bradbury EM. The kinase inhibitor staurosporine induces G1 arrest at two points: effect on retinoblastoma protein phosphorylation and cyclin-dependent kinase 2 in normal and transformed cells. Cancer Res 1994; 54: 5959-63. [PubMed: 7954429]

[23]. Antimicrobial Drug Resistance: Report by the Secretariat. A67/39, 1-5. 2014 Geneva, Switzerland, World Health Organization.

[24]. Hernandez V, Crepin T, Palencia A, et al. Discovery of a novel class of boron-based antibacterials with activity against gram-negative bacteria. Antimicrob Agents Chemother 2013; 57: 1394-403. [PubMed: 23295920]

[25]. Monteferrante CG, Jirgensons A, Varik V, Hauryliuk V, Goessens WH, Hays JP. Evaluation of the characteristics of leucyl-tRNA synthetase (LeuRS) inhibitor AN3365 in combination with different antibiotic classes. Eur J Clin Microbiol Infect Dis 2016; 35: 1857-64. [PubMed: 27506217] 
[26]. Gudzera OI, Golub AG, Bdzhola VG, et al. Identification of Mycobacterium tuberculosis leucyltRNA synthetase (LeuRS) inhibitors among the derivatives of 5-phenylamino-2H[1,2,4]triazin-3-one. J Enzyme Inhib Med Chem 2016; 31: 201-7. [PubMed: 27241561]

[27]. Martinis SA, Plateau P, Cavarelli J, Florentz C. Aminoacyl-tRNA synthetases: a new image for a classical family. Biochimie 1999; 81: 683-700. [PubMed: 10492015]

[28]. Yao P, Poruri K, Martinis SA, Fox PL. Non-catalytic regulation of gene expression by aminoacyltRNA synthetases. Top Curr Chem 2014; 344:167-87. [PubMed: 23536244]

[29]. Hornig-Do HT, Montanari A, Rozanska A, et al. Human mitochondrial leucyl tRNA synthetase can suppress non cognate pathogenic mt-tRNA mutations. EMBO Mol Med 2014; 6: 183-93. [PubMed: 24413189]

[30]. Inoue K, Kumakura S, Uchida M, Tsutsui T. Effects of eight antibacterial agents on cell survival and expression of epithelialcell- or cell-adhesion-related genes in human gingival epithelial cells. J Periodontal Res 2004; 39: 50-8. [PubMed: 14687228] 


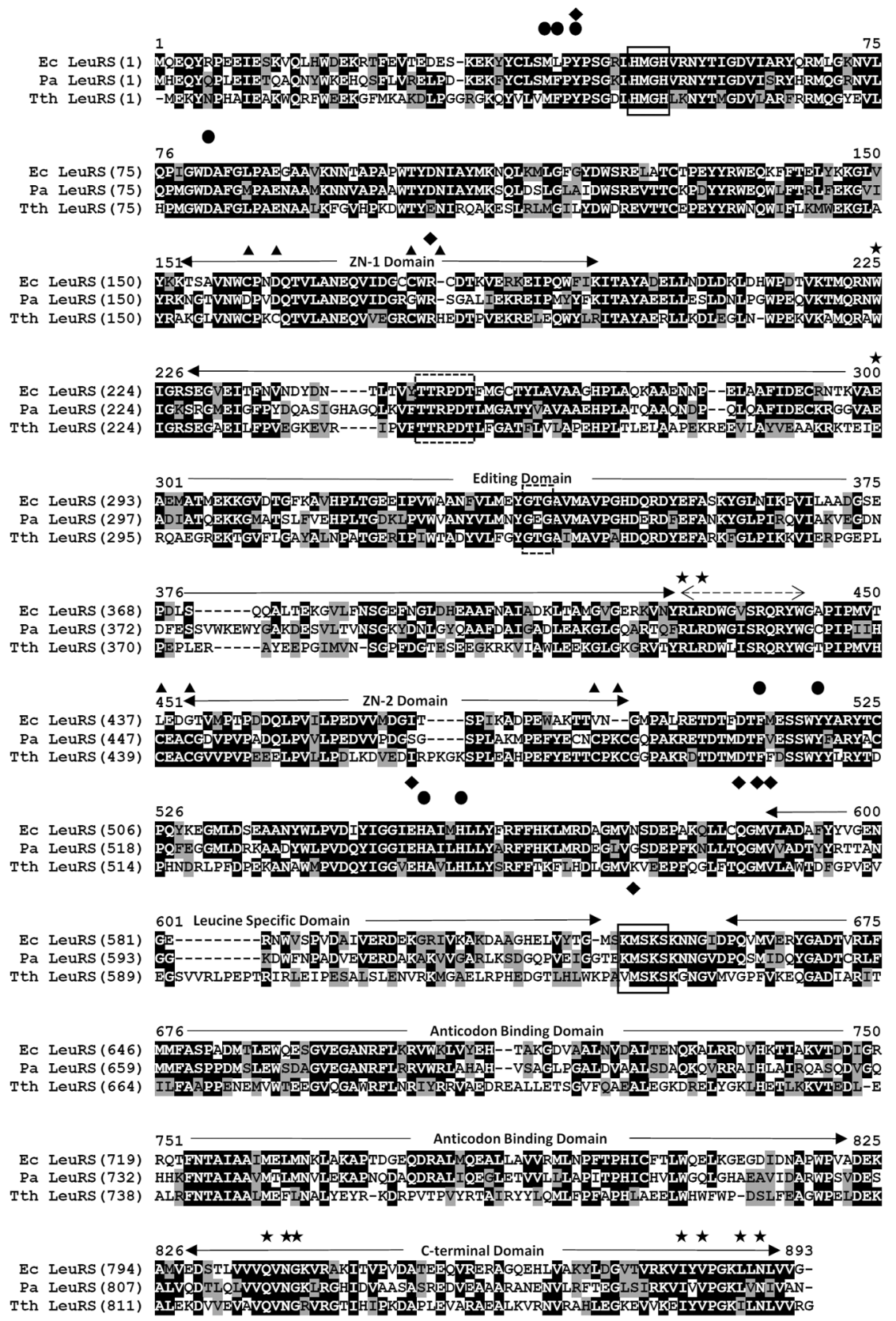

Fig. (1). An alignment of the amino acid sequence of LeuRS from P. aeruginosa, E. coli, and T. thermophilus.

The protein sequences were downloaded from the National Center for Biotechnology Information (NCBI). Accession numbers for LeuRS from E. coli (Ec), P. aeruginosa (Pa), and T. thermophilus (Tth) sequences are NP_252676, AMK98521 and BAD69984, respectively. Sequence alignments were performed using Vector NTI Advance ${ }^{(R)} 11.5$ (Invitrogen). The structural motifs, HIGH and KMSKS are enclosed by solid line boxes. The editing hydrolytic active site composed of two regions are enclosed by dashed line boxes. Specific amino acids that interact with Leu $(\bullet)$, ATP $(\diamond)$ and tRNA $(\star)$ are indicated. Cysteine and histidine residues forming zinc-binding knuckles are indicated $(\boldsymbol{\Delta})$. 


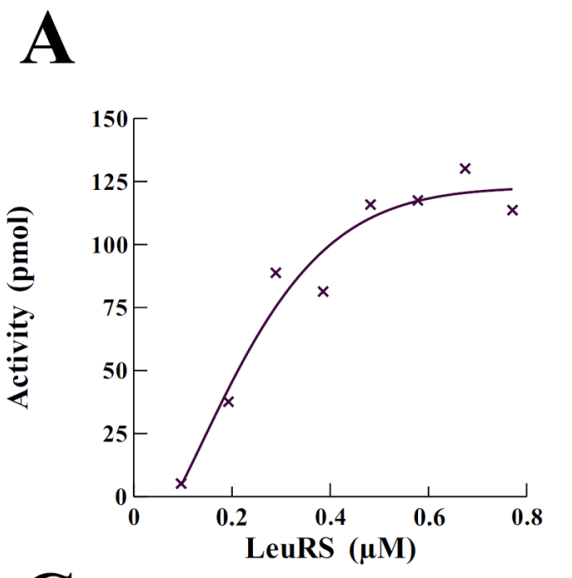

B
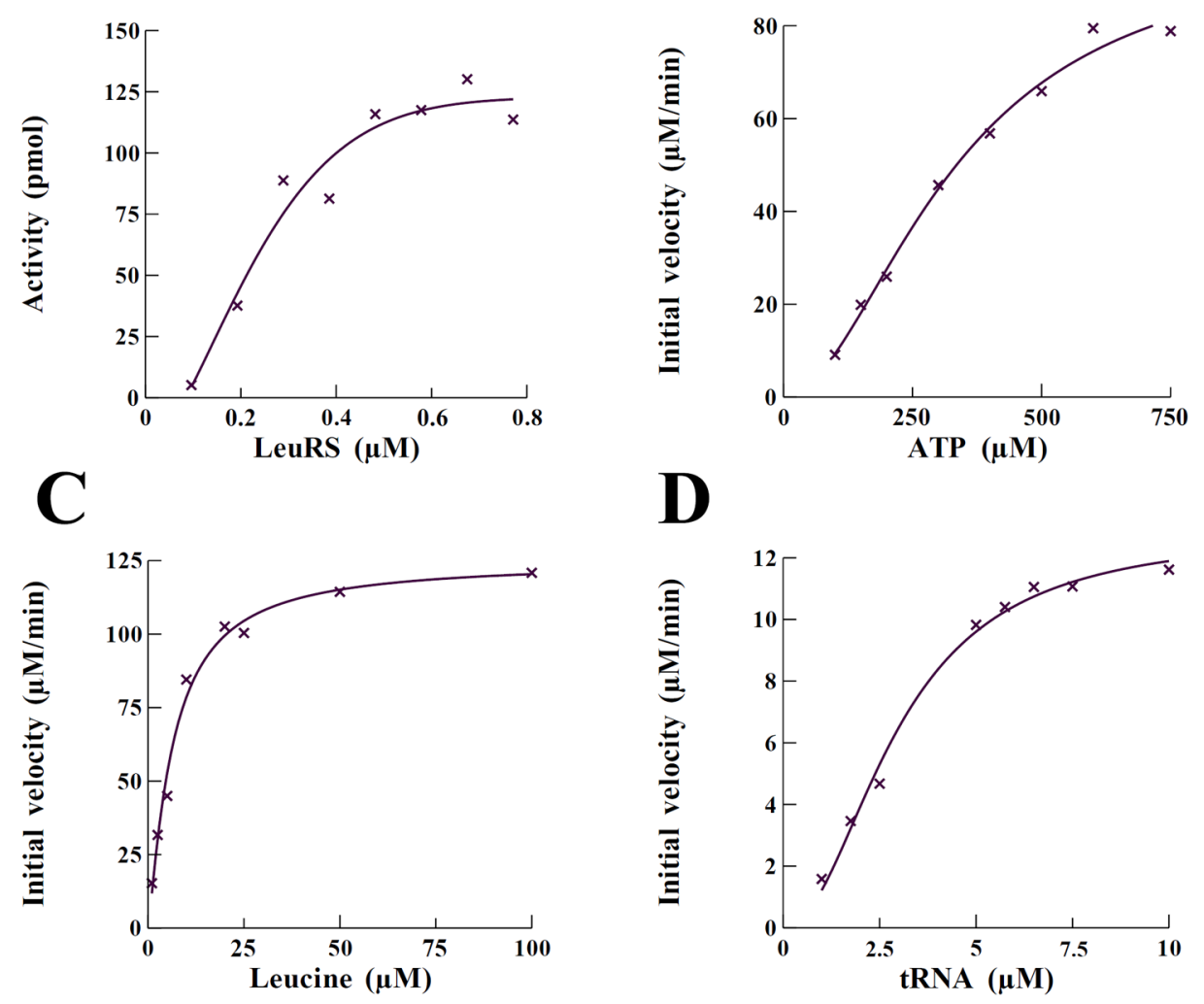

$\mathbf{E}$

\begin{tabular}{|c|c|c|c|c|c|c|c|c|}
\hline \multicolumn{3}{|c|}{ tRNA } & \multicolumn{3}{|c|}{ Leucine } & \multicolumn{3}{|c|}{$\mathbf{A T P}$} \\
\hline $\begin{array}{c}\boldsymbol{K}_{\mathbf{M}} \\
(\mu \mathrm{M})\end{array}$ & $\begin{array}{c}\boldsymbol{k}_{\mathrm{cat}}{ }^{\text {obs }} \\
\left(\mathbf{s}^{-1}\right)\end{array}$ & $\begin{array}{l}k_{\mathrm{cat}}{ }^{\mathrm{obs}} / K_{\mathrm{M}} \\
\left(\mathrm{s}^{-1} \mu \mathrm{M}^{-1}\right)\end{array}$ & $\begin{array}{c}K_{M} \\
(\mu \mathrm{M})\end{array}$ & $\begin{array}{c}k_{\mathrm{cat}^{0 \mathrm{bs}}} \\
\left(\mathrm{s}^{-1}\right)\end{array}$ & $\begin{array}{c}k_{\mathrm{cat}}{ }^{\mathrm{obs}} / K_{\mathrm{M}} \\
\left(\mathrm{s}^{-1} \mu \mathbf{M}^{-1}\right)\end{array}$ & $\begin{array}{c}K_{\mathbf{M}} \\
(\mu \mathrm{M})\end{array}$ & $\begin{array}{c}k_{\text {cat }}{ }^{\text {obs }} \\
\left(\mathbf{s}^{-1}\right)\end{array}$ & $\begin{array}{l}k_{\text {cata }}{ }^{\text {bbs }} / K_{M} \\
\left(\mathrm{~s}^{-1} \mu M^{-1}\right)\end{array}$ \\
\hline 3.0 & 0.44 & 0.15 & 6.5 & 59.4 & 9.2 & 330 & 46.9 & 0.14 \\
\hline
\end{tabular}

Fig. (2). Determination of the activity of $P$. aeruginosa LeuRS and the kinetic parameters governing interactions with its three substrates: leucine, ATP, and tRNA.

$P$. aeruginosa LeuRS was titrated into the aminoacylation assay (A) as described in "Methods and Materials" at concentrations between 0.1 and $0.8 \mu \mathrm{M}$. Background activity was minimal and was subtracted from values at all concentrations of LeuRS. Initial velocities for the interaction of LeuRS with ATP (B) and leucine (C) were both determined using the ATP:PP $P_{i}$ exchange reaction. Initial velocity for the interaction of LeuRS with tRNA were determined using the aminoacylation reaction (D). The concentration of LeuRS in the aminoacylation reactions and the exchange reactions was $0.5 \mu \mathrm{M}$ and $0.035 \mu \mathrm{M}$, respectively. Initial velocities were determined and the data were fit to a Michaelis-Menten steady-state model using XLfit 5.3 (IDBS) to determine. $K_{\mathrm{M}}$ and $\mathrm{V}_{\max }$. The kinetic parameters were determined for interaction of LeuRS with the three substrates $(\mathrm{E})$. 

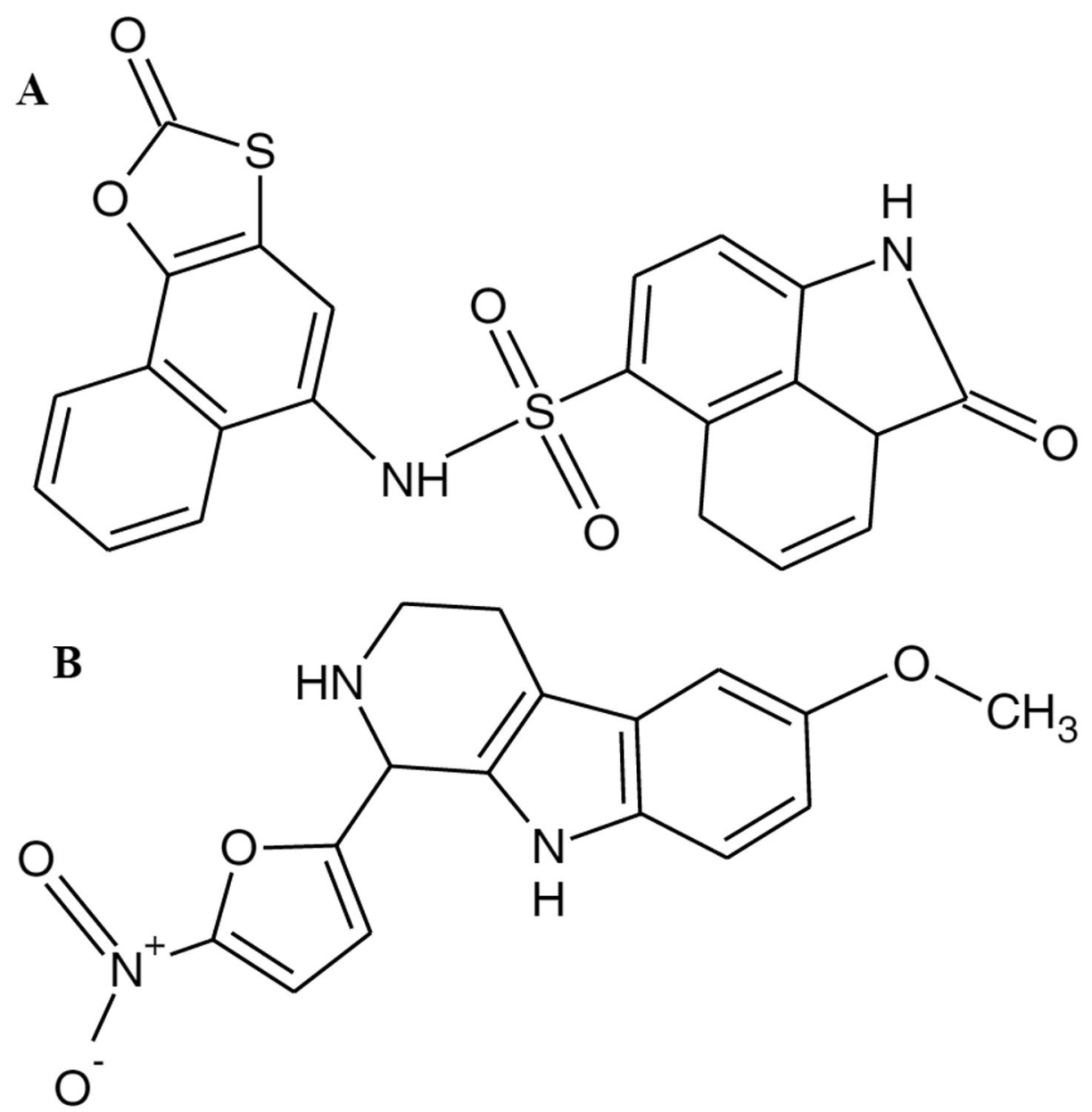

Fig. (3).

The chemical structure of the hit compounds. The structure of BT03C09 (A) and BT03E07 (B). 

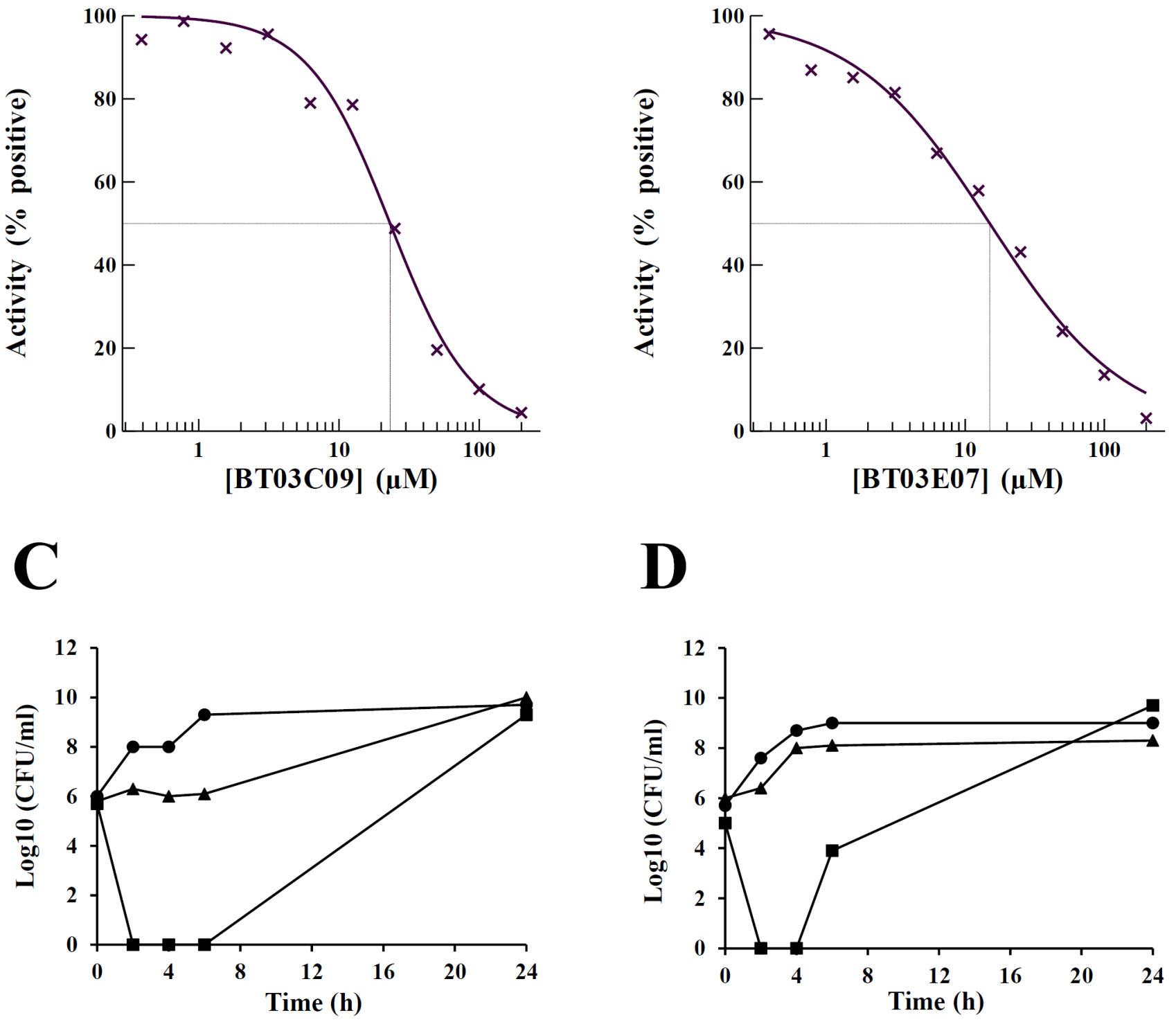

Fig. (4). Characterization of enzymatic and bacterial inhibition of BT03C09 and BT03E07. $\mathrm{IC}_{50}$ values for the inhibitory activity of BT03C09 (A) and BT03E07 (B) against $P$. aeruginosa LeuRS were $23 \mu \mathrm{M}$ and $15 \mu \mathrm{M}$, respectively. $\mathrm{IC}_{50}$ s were determined with the test compounds serially diluted from $200 \mu \mathrm{M}$ to $0.4 \mu \mathrm{M}$ into aminoacylation assays containing $P$. aeruginosa LeuRS at $0.1 \mu \mathrm{M}$. The "\% Positive" indicates the percent of activity observed relative to activity in assays where only DMSO was added to the assay in the absence of compound. The curve fits and $\mathrm{IC}_{50}$ values were determined using the Sigmoidal DoseResponse Model in XLfit 5.3 (IDBS). The activity of the hit compounds against the growth of cultures containing $(\mathbf{C})$ E. faecalis, and (D) E. coli tolC mutant bacteria were determined using broth microdilution susceptibility testing. Compounds were added to bacterial cultures at $4 \times$ MIC. Samples were analyzed by plating and determination of colony forming units $(\mathrm{CFU})$ at 0, 2, 4, 6 and $24 \mathrm{~h}$. Filled squares ( $\mathbf{\square})$ represents cultures containing BT03E07 and 
filled triangles $(\mathbf{\Delta})$ represents cultures containing BT03C09. Filled circles $(\bullet)$ represent growth of control cultures in the absence of compound. 
A
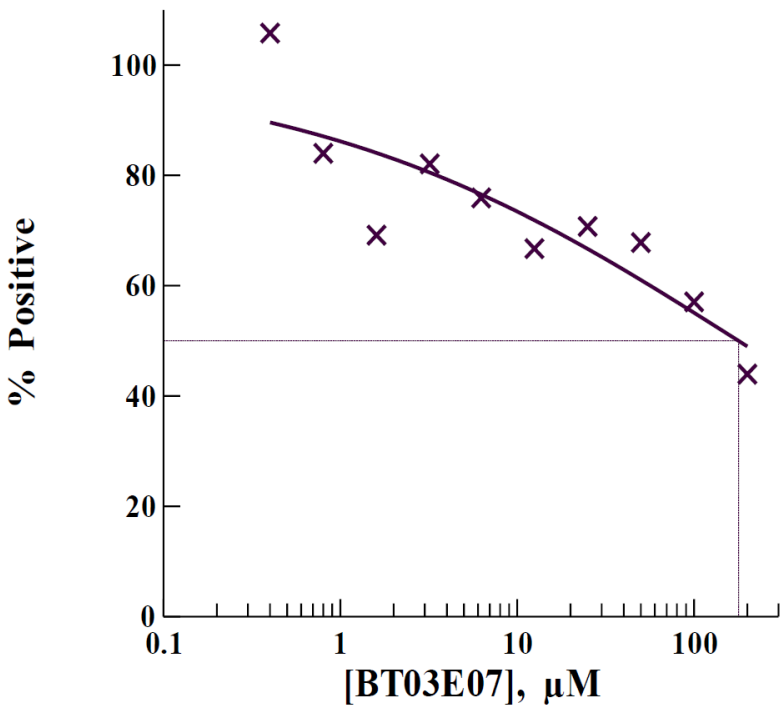

C

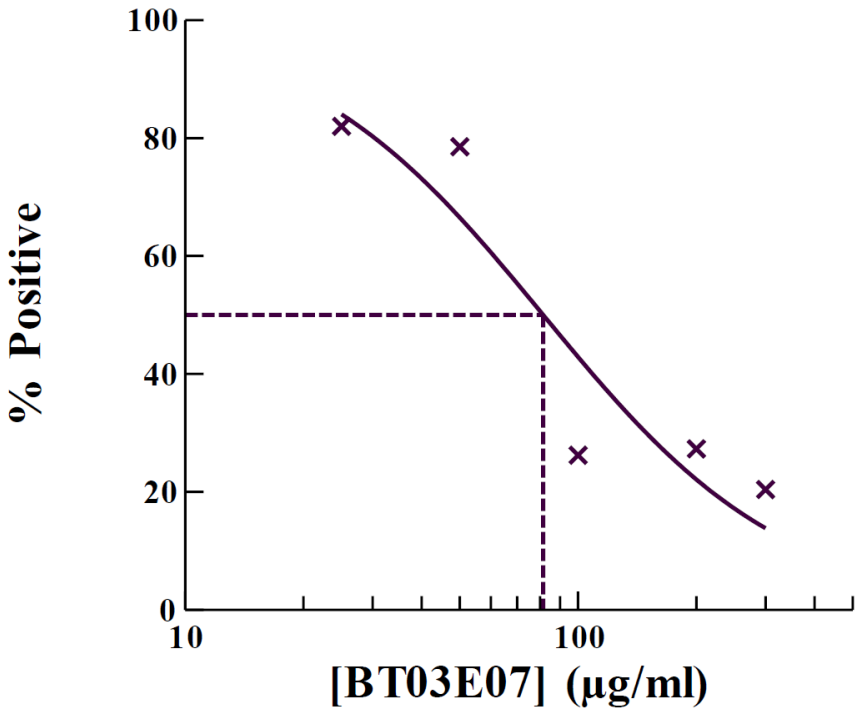

B

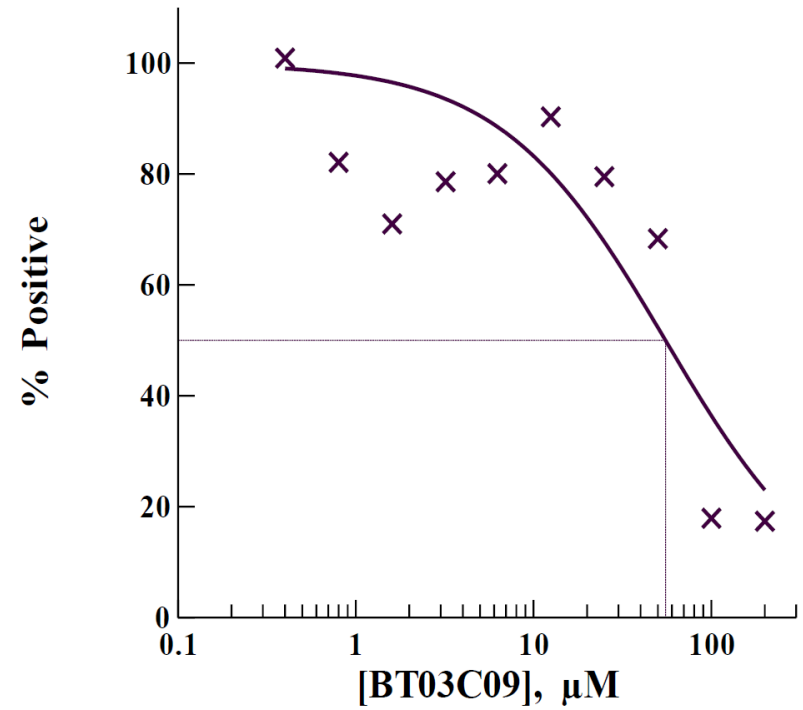

D

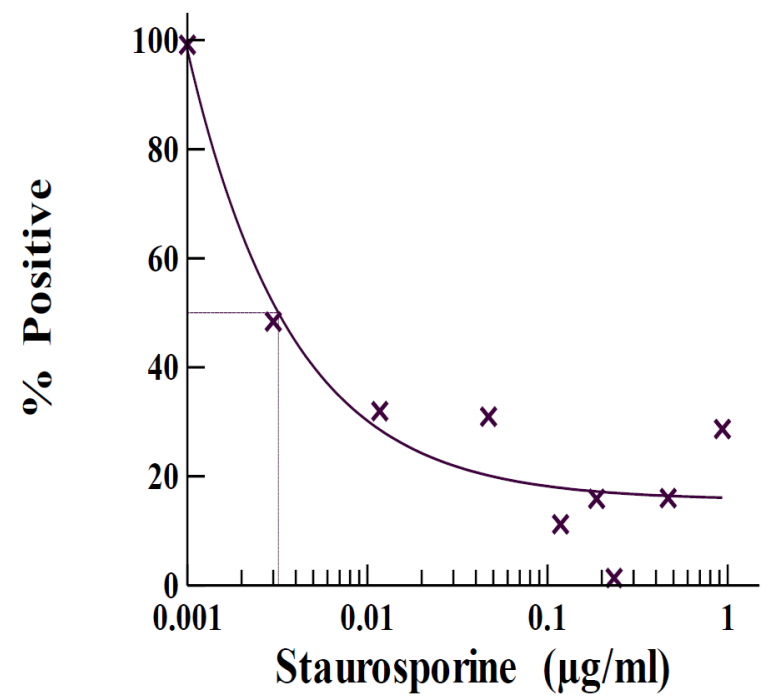

Fig. (5).

Determination of the compound inhibition of human mitochondrial LeuRS and the toxicity relative to the control staurosporine in human cell cultures. Inhibitory activity of BT03E07 (A) and BT03C09 (B) against the activity of human mitochondrial LeuRS (hmLeuRS). The concentration of hmLeuRS was $0.075 \mu \mathrm{M}$. MTT assays were performed after 24 hours exposure to the indicated dose of drug under standard tissue culture conditions as described in "Materials and Methods". To determine the $\mathrm{CC}_{50}$ of BT03E07, the compound concentration ranged from 25 to $300 \mu \mathrm{g} / \mathrm{ml}(\mathrm{C})$. The control staurosporine was serially diluted in assays from 1 to $0.001 \mu \mathrm{g} / \mathrm{ml}$ to determine $\mathrm{CC}_{50}$ (D). The data points represents an 
average value for assays carried out in triplicate. The "\% Positive" indicates the percent of activity observed relative to activity in assays where only DMSO was added to the assay in the absence of compound. The curve fits and $\mathrm{CC}_{50}$ values were determined using the Sigmoidal Dose-Response Model in XLfit 5.3 (IDBS). 
Table 1.

$P$. aeruginosa LeuRS amino acid sequence conservation (average) compared with homologs from different phyla.

\begin{tabular}{|c|c|}
\hline LeuRS & Similarity/Identity (\%) \\
\hline$\gamma$-proteobacteria & $70 / 56$ \\
\hline$\beta$-proteobacteria & $72 / 61$ \\
\hline a-proteobacteria & $59 / 45$ \\
\hline$\delta$-, $\varepsilon$-proteobacteria & $58 / 46$ \\
\hline Actinobacteria & $45 / 34$ \\
\hline Firmicutes & $55 / 42$ \\
\hline Spirochaetales & $52 / 39$ \\
\hline Chlamydiae & $52 / 39$ \\
\hline FCB & $48 / 34$ \\
\hline Human mitochondria & $47 / 33$ \\
\hline Human cytosolic & $22 / 12$ \\
\hline
\end{tabular}


Table 2.

Minimum inhibitory concentration of the hit compounds against selected bacterial.

\begin{tabular}{|c|c|c|}
\hline Bacteria & \multicolumn{2}{|c|}{ MIC $(\boldsymbol{\mu g} / \mathbf{m l})$} \\
\hline & BT03E07 & BT03C09 \\
\hline E. coli (ATCC 25922) & $128^{a}$ & 128 \\
\hline E. coli tolC (efflux mutant) & 32 & 64 \\
\hline E.faecalis (ATCC 29212) & 64 & 64 \\
\hline H. influenzae (ATCC 49766) & 64 & 64 \\
\hline P. aeruginosa (ATCC 47085) & 128 & 128 \\
\hline P. aeruginosa PAO200 (efflux mutant) & 128 & 128 \\
\hline P. aeruginosa (hypersensitive) & 128 & 128 \\
\hline S. aureus (ATCC 29213) & 128 & 64 \\
\hline S. pneumonia (ATCC 49619) & 64 & 128 \\
\hline
\end{tabular}

${ }^{a}$ The MIC for each compound against each of the bacteria was determined in three separate MIC assays. 